physician, to hyperacidity. The attack yielded somewhat to sodium bicarbonate, magnesium oxid and bismuth so that he was again able to return to his work. However, the weakness persisted and he was placed on digitalis. Subsequen: to January 25 , the salivary secretion was deficieat, and he lacked appetite and could not relish food. He continued on suprarenal treatment; epinephrin solution $1: 1,000,3$ minims, twice a day hypodermically; rectal injections of $3 / 200$ grain of the whole gland, and two capsules, 10 grains each, of whole gland, by mouth, at night. In February, the weaknes; and shortness of breath became more pronounced. He suffered from pain in the left upper portion of the chest which Dr. Sachs called "low pressure angina." The pain was relieved by heat, exertion, food and nitroglycerin.

In March, 1921, Dr. Muirhead returned to the clinic, complaining of extreme weakness which confined him to bed and of pain in the left shoulder. The pigmentation was marked. He was extremely asthenic, and suffered almost constantly from gastro-intestinal symptoms, especially burning in the stomach. The heart was slightly enlarged and the sounds were of poor quality. An electrocardiogram disclosed a rate of 92 , sinus tachycardia, notched QRS complex in all leads, arborization block, and slight right ventricular preponderance. The blood pressure was 86 systolic and 54 diastolic; the blood urea was $56 \mathrm{mg}$. for each hundred cubic centimeters, and the uric acid $2.8 \mathrm{mg}$. The hemoglobili was 68 . per cent., and the erythrocytes numbered $3,820,000$. The patient ate very sparingly, and toward the end of his stay developed a mild acidosis. He left the clinic, March 23, unimproved. The subsequent course of the disease is submitted in Dr. Sachs' report:

"The blood pressure just prior to his death was 84 systolic and 60 diastolic. Dr. Muirhead had a mild acidosis from time to time, for which he was given alkalis. Alkalis during the latter part of his illness distressed him greatly and were discontinued. His gastric acidity changed from a hyperacidity to a hypo-acidity. He progressively became more asthenic until it became difficult for him to swallow. He gradually lapsed into coma, and died, April 26, 1921."

\section{REVIEW OF CASE}

Clinically, Dr. Muirhead presented a typical, slowly progressing case of chronic Addison's disease with pigmentation, marked asthenia, intestinal discomfort, and low blood pressure. He gave a questionable history of renal tuberculosis; but tuberculosis was not borne out at operation, a right side nephrectomy being performed in 1918.

Subsequent to the nephrectomy, gout developed; the patient suffered from typical attacks of great severity, involving the metatarsophalangeal joints associated with high level of uric acid in the blood. Both the gout and blood uric acid responded promptly and permanently to a low purin diet. It is of interest to speculate on whether or not the removal of the kidney was a factor in the increase of the blood uric acid and in the development of gout.

The patient's improvement under treatment with epinephrin and the whole suprarenal gland during the first visit to Rochester, and after his return home, was striking objectively as well as subjectively. Rectal injections of epinephrin proved effective for a considerable period, although they were finally discontinued because of tenesmus. Glandular therapy was of unquestionable value in the relief of asthenia and of gastro-intestinal discomfort, and resulted in a temporary clearing up of pigmentation. For a time, at least, it also checked the general course of the disease.

Although the results were only temporary, they were almost miraculous. Such definite relief of symptoms in the chronic form of the disease justifies a thorough trial of such measures in other cases of Addison's disease.

\section{Clinical Notes, Suggestions, and New Instruments}

\section{NEW ANGULAR UTERINE DRESSING AND SPONGE HOLDING FORCEPS}

Albert M. Crance, M.D., Geneva, N. Y.

The instrument shown in the accompanying illustration was designed chiefly for use as sponge-holding forceps for

medication through a
vaginal speculum, as
well as to serve as
sponge-holding for-
ceps for employment
in gynecologic sur-
gery. The inst $\mathrm{r}$ u-
ment is shaped in.
such a way as to per-
mit direct entrance into the
speculum, and, because of the
angular arrangement of the
handle, the operating hand is
entirely below the operator's line of
vision,
There is a catch provided between
the ring handles for keeping the
forceps locked during the dressing
or sponging manipulation.
The size of the instrument corre-
sponds to the size of the average
speculum in use. It is now in
process of manufacture by the Kny-
Scheerer Corporation.
Schnirel Building.

A METHOD FOR. MAINTAINING PRESSURE OVER ELBOW IN' OLECRANON BURSITIS (MINER'S ELBOIV), WITHOUT IMMOBILIZING THE JOINT

Guy S. Van alstine, M.D., Chicago

The usual treatment of a recent olecranon bursitis with nonpurulent effusion is aspiration, followed by bandage or adhesive strap pressure to favor adhesion of the bursal

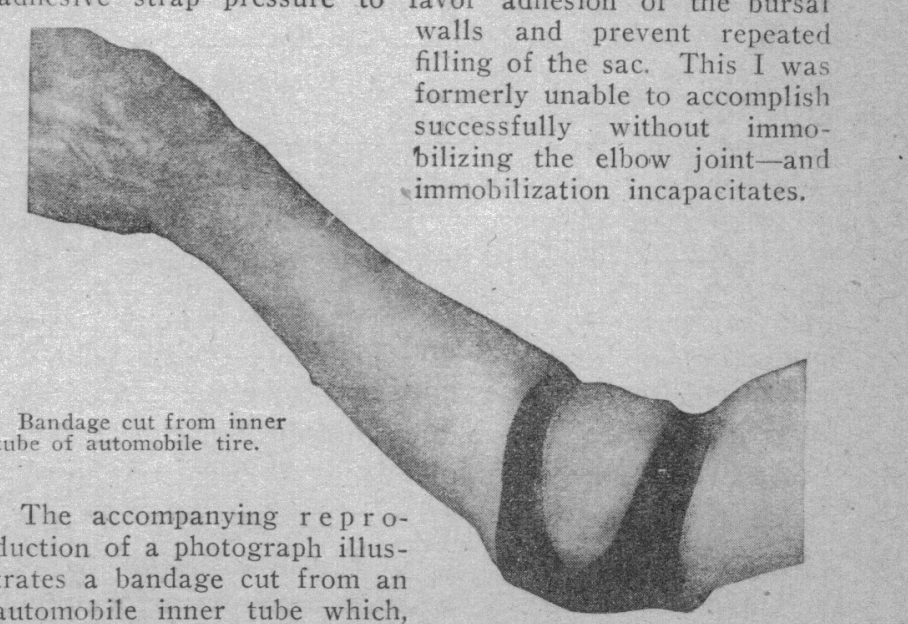

I find, will maintain sufficient pressure to bring about obliteration of the bursal sac without greatly inhibiting the joint action. With this device my patients have been able to continue their usual occupations while under treatment. This treatment is not suitable in old chronic cases with thickened, fibrous sacs, or in acute suppurative bursitis.

2678 East Seventy-Fifth Street. 